\title{
Fluid Resuscitation for Refractory Hypotension
}

\author{
Alexander Valverde* \\ Department of Clinical Studies, Ontario Veterinary College, University of Guelph, Guelph, ON, Canada
}

Hypotension is a common occurrence, especially in anesthetized patients and in critical patients suffering from hypovolemia due to shock and sepsis. Hypotension can also occur in normovolemic animals, anesthetized or conscious, under conditions of vasodilation or decreased cardiac function. The main consequence of hypotension is decreased organ perfusion and tissue injury/dysfunction. In the human literature there is no consensus on what is the threshold value for hypotension, and ranges from $<80$ to $<100 \mathrm{mmHg}$ for systolic blood pressure and from $<50$ to $<70 \mathrm{mmHg}$ for mean arterial blood pressure have been referenced for intraoperative hypotension. In veterinary medicine, similar values are referenced, despite marked differences in normal arterial blood pressure between species and with respect to humans. Therapeutic intervention involves fluid therapy to normalize volemia and use of sympathomimetics to enhance

OPEN ACCESS

Edited by:

Deborah Silverstein, University of Pennsylvania,

United States

Reviewed by:

Jane Quandt,

University of Georgia, United States Ciara Barr,

University of Pennsylvania,

United States

*Correspondence:

Alexander Valverde

valverde@uoguelph.ca

Specialty section:

This article was submitted to

Comparative and Clinical Medicine, a section of the journal

Frontiers in Veterinary Science

Received: 26 October 2020

Accepted: 01 February 2021

Published: 10 March 2021

Citation:

Valverde A (2021) Fluid Resuscitation for Refractory Hypotension.

Front. Vet. Sci. 8:621696.

doi: 10.3389/fvets.2021.621696 cardiac function and regulate peripheral vascular resistance. Despite these therapeutic measures, there is a subset of patients that are seemingly refractory and exhibit persistent hypotension. This review covers the physiological aspects that govern arterial blood pressure control and blood flow to tissues/organs, the pathophysiological mechanisms involved in hypotension and refractory hypotension, and therapeutic considerations and expectations that include proper interpretation of cardiovascular parameters, fluid recommendations and therapy rates, use of sympathomimetics and vasopressors, and newer approaches derived from the human literature.

Keywords: anesthesia, cardiac output, hypotension, sepsis, vasodilation

\section{INTRODUCTION}

\section{What Is Hypotension?}

In simple terms, hypotension is a lower than normal arterial blood pressure. However, this definition does not imply when and at what specific values is hypotension harmful to the patient. Hypotension is a common occurrence, especially in anesthetized animals and in critical patients suffering from hypovolemia due to shock and sepsis.

Mean arterial blood pressure values of $60 \mathrm{mmHg}$ or less and systolic arterial blood pressure values of $80 \mathrm{mmHg}$ or less have been reported as indicative of excessive hypotension in animals, and ideally these pressures should be maintain above $80 \mathrm{mmHg}$ and $100 \mathrm{mmHg}$ for mean and systolic arterial blood pressure, respectively (1). However, arterial blood pressure values vary among species (Table 1), so the use of a common value as the threshold value for all species is not accurate and is best to keep in mind specific species values during the assessment of low arterial blood pressures. In addition, arterial blood pressure is consistently lower in the anesthetized than in conscious patients.

In humans, where studies have been completed with sufficient statistical power, there is still no 
TABLE 1 | Normal arterial blood pressure $(\mathrm{mmHg})$ and cardiac index $(\mathrm{mL} / \mathrm{kg} / \mathrm{min})$ in different species.

\begin{tabular}{|c|c|c|c|c|c|}
\hline & \multicolumn{4}{|c|}{ Conscious } & \multirow[t]{2}{*}{ References } \\
\hline & Systolic & Diastolic & Mean & Cardiac index & \\
\hline Human & 120 & 80 & 93 & $71-86$ & (2) \\
\hline Dog & 150 & 98 & 115 & 165 & $(3,4)$ \\
\hline \multirow[t]{3}{*}{ Cat } & $108-120$ & $79-87$ & $92-103$ & 200 & $(5,6)$ \\
\hline & $130-151$ & $94-115$ & $113-140$ & NR & (7) \\
\hline & NR & NR & $142-165$ & NR & (8) \\
\hline \multirow[t]{2}{*}{ Horse } & 147 & 92 & 115 & 60 & (9) \\
\hline & 163 & 100 & 125 & 79 & (10) \\
\hline Cattle & 155 & 105 & 123 & 119 & $(11)$ \\
\hline Sheep & 125 & 96 & 109 & 144 & (11) \\
\hline Goat & 105 & 70 & 86 & 132 & (11) \\
\hline Rabbit & 100 & 65 & 75 & $104-237$ & $(12-15)$ \\
\hline
\end{tabular}

NR, not reported.

consensus on what is the threshold value for hypotension to provide a widely accepted definition (16-18) and this is further complicated when adults are compared to pediatric patients (19) because arterial blood pressure is consistently lower in the latter population.

\section{ARTERIAL BLOOD PRESSURE}

\section{Physiology for Arterial Blood Pressure Control}

The major function of the nervous system on the circulatory system is to control arterial blood pressure by allowing adequate and independent blood flow to the individual needs of tissues and organs, and regardless of the amount of blood that flows to any given tissue, arterial blood pressure remains constant (20).

Arterial blood pressure control is necessary for short- and long-term situations, and it differs between. Short-term refers to acute changes (usually minutes to hours), whereas longterm refers to chronic changes (hours to weeks). Short-term control occurs through changes that affect both cardiac output and arterial blood pressure, and include variations in vascular resistance and compliance, contractility, heart rate and blood volume (Figure 1) (20). An example of short-term control are changes that occur during exercise in all or most of the factors (resistance, compliance, contractility, heart rate), to increase arterial blood pressure and cardiac output to meet tissue demands, but the increase in cardiac output exceeds that of arterial blood pressure because local muscle activity results in a decrease in vascular resistance (vasodilation) to improve blood flow while veins and small arterioles of other tissues exhibit a decrease in vascular compliance (constriction) to improve venous return (20). If arterial blood pressure and cardiac output do not meet tissue demands, there is less provision of nutrients and oxygen and the onset of anaerobic activity (21).

Individually, each of these factors result in specific changes in arterial blood pressure and/or cardiac output; however, with an intact nervous system it is the interaction between factors that determines the final cardiovascular effect. In simple terms, Ohm's Law [electrical current (I) through a conductor is proportional to voltage $(\mathrm{V})$ and inversely proportional to resistance $(\mathrm{R}),(\mathrm{I}=\mathrm{V} \div$ $\mathrm{R})$ ] can be used to define the interaction between arterial blood pressure and cardiac output, where I is equivalent to cardiac output (CO), $\mathrm{V}$ is arterial blood pressure (ABP), and $\mathrm{R}$ is vascular resistance $(\mathrm{VR})$, so that $\mathrm{CO}=\mathrm{ABP} \div \mathrm{VR}$. For example, vascular resistance on its own can affect arterial blood pressure and cardiac output in opposite ways, a decrease in vascular resistance lowers arterial blood pressure and could increase cardiac output, whereas an increase in vascular resistance results in higher arterial blood pressure and limits cardiac output (20).

Volume administration increases cardiac output by increasing preload, and can potentially increase arterial blood pressure if the nervous system does not exert a reflex control over vascular resistance. This effect of volume administration without a change in arterial blood pressure is notable in conditions of normovolemia, where an increase in circulating volume results in a decrease in vascular resistance $(20,22,23)$ and the compliance of the vascular system and tissues can store a significant volume, blunting any change in circulating volume $(20,22-25)$. If the decrease in vascular resistance was prevented during fluid administration in a normovolemic patient with a vasoconstrictor, then arterial blood pressure could also increase in conjunction with cardiac output (20). This is often observed with use of alpha-adrenergic drugs (vasoconstriction) but only if contractility can overcome the increase in vascular resistance (afterload) (26-29). The benefits of volume administration to increase arterial blood pressure are obvious in conditions where there is an ongoing deficit in circulating volume (hypovolemia).

An increase in heart rate can result in an increase in cardiac output and arterial blood pressure, but only if the circulating volume is ideal. A low circulating volume (hypovolemia) results in low venous return (preload) and a low right atrial pressure, even below $0 \mathrm{mmHg}$. The veins entering the chest will collapse with subatmospheric pressures and without proper preload the cardiac output and arterial blood pressure do not benefit from an increase in heart rate (20). Conversely, if preload is increased, an increase in heart rate is beneficial to cardiac output and arterial blood pressure, because it helps eject effectively the returning blood back into the circulation. However, an excessive increase in heart rate is not beneficial because diastolic time is shortened and decreases stroke volume, in addition to increasing the work of the heart, which weakens the heart contractility, all of which affect cardiac output negatively.

Long-term control of cardiac output and arterial blood pressure is the result of adaptation of baroreceptors within hours to days to changes in circulating volume and arterial blood pressure, of the instauration of higher vascular resistance that results in higher arterial blood pressure and minimal changes in cardiac output, and of an active participation of the kidney that responds to the increase in arterial blood pressure with endocrine and electrolyte mechanisms to control pressure and volume by increasing urinary output (20). 


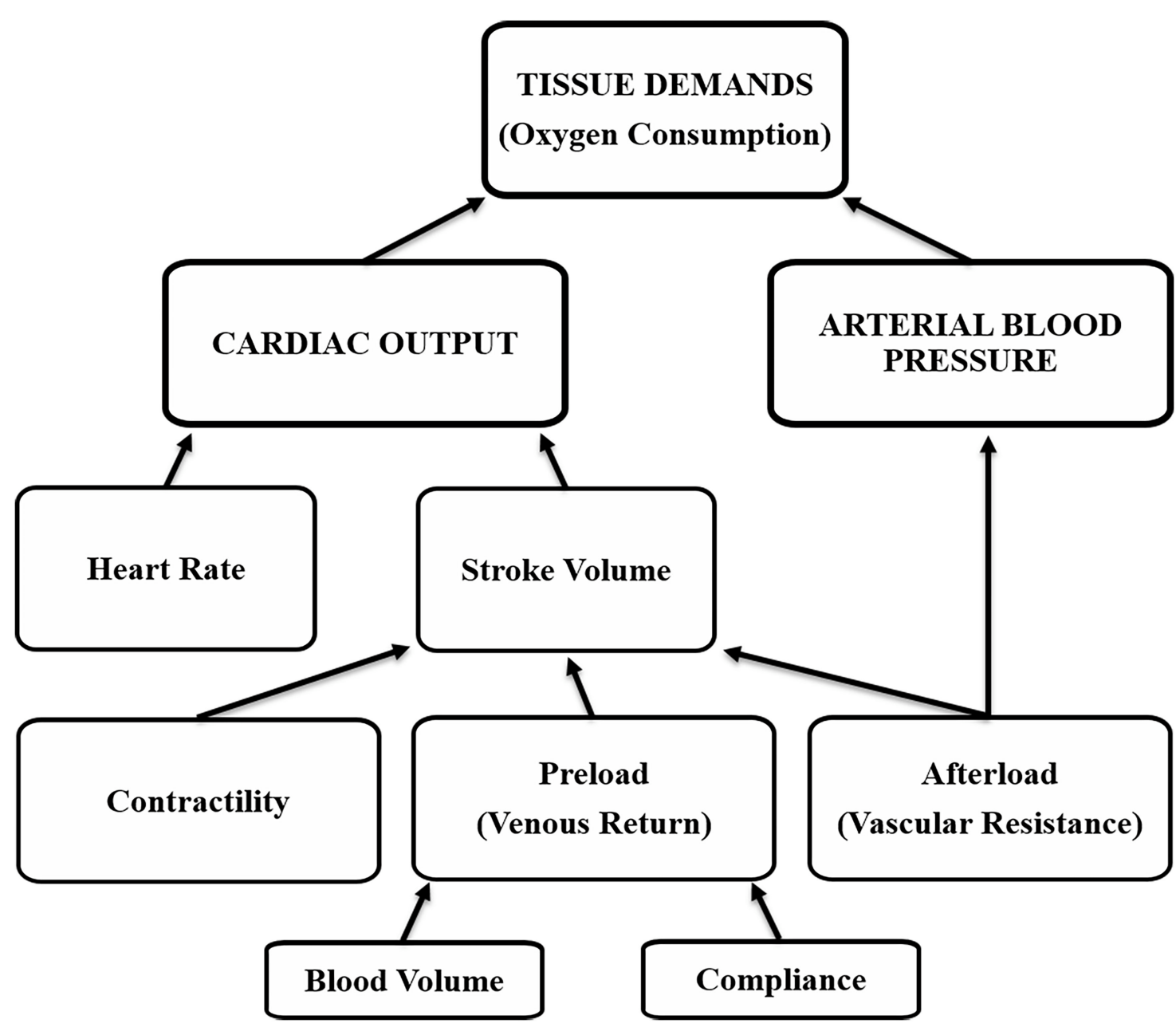

FIGURE 1 | Tissue oxygen demands are met by cardiovascular factors that affect cardiac output and arterial blood pressure.

\section{Hypotension and Tissue Perfusion}

Hypotension has been associated with decreased organ perfusion and injury/dysfunction, which in humans may include myocardial infarction $(17,30,31)$, acute kidney injury $(17,31-34)$ and increased mortality $(30,35)$.

In general, most studies in humans have associated mean arterial blood pressures of $\leq 55 \mathrm{mmHg}$ with adverse cardiacand renal-related outcomes, and the duration of the hypotensive episode increases the risk of that adverse outcome $(17,18,31$, 34). Even at mean arterial blood pressures just $<80 \mathrm{mmHg}$, a hypotensive episode of more than $10 \mathrm{~min}$ can increase the risk of organ injury, and at lower pressures, less time is required for increased risk (18). Interestingly, improving cardiac index by $21 \%$ and mean arterial blood pressure from 65 to $85 \mathrm{mmHg}$ with norepinephrine in septic human patients did not result in better renal function than in patients kept at the lower arterial blood pressure and cardiac index (36); likewise, in research dogs, acepromazine intramuscular administration as premedication resulted in a mean arterial blood pressure of $66 \mathrm{mmHg}$ due to its vasodilatory effects, during isoflurane anesthesia for $2.25 \mathrm{~h}$, lower than pressures in the same dogs after saline administration (87 $\mathrm{mmHg}$ ), but creatinine levels, ALP-creatinine ratio in urine, and renal blood flow and glomerular filtration rate (GFR) assessed with scintigraphy were similar and within normal ranges in both groups (37).

Several aspects need to be considered to interpret hypotension. First of all, the threshold value for hypotension should not be generalized between conscious and anesthetized patients, since as stated before, values differed in the two situations and values also differ between species. A patient positioned in recumbency (dorsal, ventral, lateral) position, as it happens during anesthesia, offers the heart ideal work conditions because the effect of gravity is reduced by leveling all organs and tissues with the heart, and therefore changes to increase vascular resistance become less necessary in stable patients. In the standing position, gravitational forces result in lower pressures in the upper part of the body and higher pressures in the lower part of the body, which is counteracted by an increase 
in arterial vascular resistance and pulse rate, so that mean arterial blood pressure remains constant or slightly elevated throughout the body (38). In addition, in the standing patient, cardiac output decreases due to the increase in vascular resistance, and tissues can have a reduction in blood flow, including the kidney, which decreases GFR and increases arginine vasopressin (antidiuretic hormone) (38). General inhalant anesthesia and recumbency usually results in vasodilation and a decrease in vascular resistance, which helps maintain cardiac output if contractility is adequate, despite the reduction in mean arterial blood pressure. This could help explain why despite low mean arterial blood pressure in anesthetized patients, renal blood flow and function can remain normal in some studies $(36,37)$. Furthermore, the additional decrease in vascular resistance caused by drugs like acepromazine due to its alpha-blockade, allows for GFR and renal blood flow to be maintained within normal limits during general anesthesia, unlike conscious dogs maintained in lateral recumbency, where mean arterial blood pressures of $<80$ $\mathrm{mmHg}$ decreased GFR but not renal blood flow, which was also impaired if mean arterial blood pressure was $<66 \mathrm{mmHg}$ (39). These studies demonstrate that if the decrease in mean arterial blood pressure is the result of a decrease in vascular resistance, while contractility (cardiac output) is acceptable, an anesthetized patient can tolerate these pressures if not excessively low or for too long, and maintain adequate blood flow to tissues for their normal function.

It is also difficult to conclude when hypotension is significant enough to result in an adverse outcome, which is further confounded by how hypotension is defined in any study. Findings from different studies cannot be generalized because small changes in the selected threshold values for hypotension among human studies can result in wide differences in the incidence of intraoperative hypotension (5-99\%) and do not necessarily reflect organ dysfunction as a consequence of hypotension (16). More importantly, the variation in adverse outcomes as it relates to hypotension can be explained in part by the health status of the patient [American Society of Anesthesiologists (ASA) classification] and whether pre-existing hypovolemia or cardiac disease are the primary causes, since morbidities and mortality are associated with older age and higher ASA status risk in human patients $(17,18,30,31,33,35)$.

Studies in healthy dogs and foals under research conditions, where hypotension was induced by deep anesthesia with inhalant anesthetics in normovolemic conditions, resulted in no adverse outcomes despite mean arterial blood pressures of $24 \mathrm{mmHg}$ for at least $15 \mathrm{~min}$ in foals (26) and $46 \mathrm{mmHg}$ for at least $45 \mathrm{~min}$ in dogs (23), although pressures were normalized in those animals before recovery from anesthesia.

\section{REFRACTORY HYPOTENSION}

Hypotension that persists, despite appropriate therapeutic measures that consistently correct it, probably exhibit refractory hypotension. Refractory hypotension is most commonly encountered under conditions of shock due to hypovolemia or sepsis, but can also include cardiogenic, neurogenic, and anaphylactic shock (40). Refractory hypotension and shock develops in nearly $6 \%$ of critically ill human patients (41) and mortality rates are usually $>40-50 \%$ because of progressive hypotension $(42,43)$.

\section{Hypovolemic Shock}

Hypovolemic (hemorrhagic) shock is due to a reduced intravascular volume (preload), which results in low cardiac output and arterial blood pressure. In human medicine hypovolemic shock is rated into four classes, from least to most critical, according to the "Advanced Trauma Life Support (ATLS $\left.{ }^{\circledR}\right)$ " guidelines of the American College of Surgeons. The patient is allocated to one of the classes according to degree of blood loss ( $<15 \%$ in Class I, $15-30 \%$ in Class II, 30-40\% in Class III, and $>40 \%$ in Class IV) and degree of alteration of vital signs, including pulse rate, blood pressure, pulse pressure, respiratory rate, mental status, and urinary output (44). However, not every trauma patient fits the description of any single class and only in classes III and IV is hypotension a clinical sign (44).

In conscious, splenectomized research dogs, removal of 43 $\mathrm{mL} / \mathrm{kg}$ of blood [53\% of blood volume; (45)] in $10 \mathrm{~min}$ resulted in an immediate drop in mean arterial blood pressure from 106 $\mathrm{mmHg}$ to $25 \mathrm{mmHg}$ and a gradual recovery over $72 \mathrm{~min}$ to a decompensated mean arterial blood pressure of $61 \mathrm{mmHg}$ (46). During this period, dogs were untreated and heart rate increased from 81 beats/min before hemorrhage to over 186 beats/min, and both plasma total protein and packed cell volume decreased. Over the next hour, mean arterial blood pressure decreased again to the initial drop and heart rate was over 220 beats/min, to which the dogs succumbed to death (46).

The response to blood loss is different under conditions of general anesthesia, both with inhalant and injectable anesthetics, because these drugs inhibit, in a dose-dependent fashion, baroreceptor reflex and sympathetic activity, which interferes with normal short-term control (47-49). In addition, blood loss in itself results in decreased requirements of inhalant anesthetics (50), which deems the patient at a deeper level of anesthesia during the hypovolemic episode and further inhibits any sympathetic response. In anesthetized research dogs, maintained at an end-tidal isoflurane concentration of 1.27 to $1.74 \%[\sim 1.0-1.3$ times the minimum alveolar concentration (MAC)] to induce a mean arterial blood pressure to $65 \mathrm{mmHg}$, removal of $\sim 25 \mathrm{~mL} / \mathrm{kg}$ of blood (31\% of blood volume) over 30 min resulted in inhalant anesthetic dose-dependent effects: no change in arterial pressure with lighter anesthesia to a drop to 45 $\mathrm{mmHg}$ with deeper anesthesia, heart rate can remain unchanged or increase slightly with lighter anesthesia and decrease slightly with deeper anesthesia, cardiac index and stroke volume may not change with lighter anesthesia and decrease with deeper anesthesia, systemic vascular resistance not change or increase slightly, and total protein and packed cell volume had not changed with the bleeding $(51,52)$. A similar blood loss of 30 $\mathrm{mL} / \mathrm{kg}$ in one study decreased MAC by $16 \%$ (50) and it is likely that some of the observed changes are also influenced by the increased MAC multiple (if MAC decreases by $16 \%$ and the end-tidal inhalant concentration is not adjusted, MAC becomes $1.16 \%$ higher); therefore, under clinical conditions is important 
to consider adjusting the anesthetic plane during hemorrhage to avoid the contribution of a higher MAC multiple on blood loss and its negative effect on the inhibition of baroreflexes and sympathetic activity (53).

\section{Septic Shock}

Septic shock is discussed in depth in the chapter "Fluid Therapy in Dogs and Cats with Sepsis." In brief, septic shock is a type of distributive shock, in which infection results in organ dysfunction due to a dysregulated response from the patient that results in injury to its own tissues and organs (43). Patients with sepsis exhibit hypotension due to peripheral vasodilation, so septic shock is also known as vasodilatory shock or a state of vasoplegia, and is the most common form of shock encountered in intensive care units $(43,54)$. The pathophysiological mechanisms, responsible for vasoplegia and decrease vascular responsiveness in septic shock, result in refractory hypotension and are also common to hypovolemic shock, cardiogenic shock and anaphylactic shock (40).

According to the latest consensus for sepsis and septic shock in humans (Sepsis 3.0), patients clinically exhibit persistent hypotension that requires of vasopressors to maintain a mean arterial blood pressure $\geq 65 \mathrm{mmHg}$ and a serum lactate level $>2 \mathrm{mmol} / \mathrm{L}$, despite adequate volume resuscitation and the absence of hypovolemia (43). In addition, despite adequate tissue perfusion achieved with ideal mean arterial blood pressure and normovolemia, cells undergo conditions of dysoxia (i.e., inability to match oxygen demand with oxygen supply), which results in organ dysfunction and high lactate levels and results in mortality rates in excess of $40 \%$ in human patients (43) and veterinary patients (55-64).

\section{Mechanisms Responsible for Refractory Hypotension}

The vasodilation that results from sepsis is the result of several factors that enhance vasodilatory- and inhibit vasoconstrictor mechanisms. These include an unregulated synthesis of nitric oxide, a potent vasodilator, in response to cytokines released during septic and hemorrhagic shock. In dogs with septic peritonitis, levels of the inflammatory cytokines C-C motif chemokine ligand 2 (CCL2) and interleukin 6 (IL-6) were significantly higher than in non-septic dogs (64), which contributes to migration and infiltration of macrophages into the area of insult (65). Nitric oxide is produced from L-arginine by nitric oxide synthase, present in endothelial cells, and diffuses into the underlying smooth muscle to activate soluble guanylate cyclase and cGMP production that dephosphorylates myosin, via the myosin light chain phosphatase, causing vasorelaxation $(54,66,67)$.

Another mechanism is the result of conditions of local acidosis, with hydrogen ions and lactic acid production from anaerobic metabolism $(43,56,60,64,68,69)$. These conditions result in opening of ATP-sensitive potassium channels present in the plasma membrane of vascular smooth muscle and allow an efflux of potassium that hyperpolarizes the plasma membrane and prevents calcium from entering the cell; without intracellular calcium, the phosphorylation of myosin is prevented and the smooth muscle does not contract $(54,66,70)$. Metabolic acidosis also promotes overproduction of nitric oxide (70).

The prostaglandin prostacyclin is found in increased concentrations in conditions of septic shock (71). Prostacyclin forms from arachidonic acid from the vascular endothelium by the actions of the cyclooxygenase enzymes and prostacyclin synthase, and once formed it binds to the prostacyclin receptor (IP) and acts on a G-protein coupled receptor which activates adenyl cyclase and stimulates the formation of c-AMP from ATP, which activates protein kinase A and prevents increases in cytoplasmic $\mathrm{Ca}^{2+}$, preventing vasoconstriction and resulting in vasodilation (67).

A final mechanism involves depletion of vasopressin reserves from the neurohypophysis (66). Vasopressin is a potent vasoconstrictor by acting on vasopressin-type 1a receptors $\left(\mathrm{V}_{1 \mathrm{a}}\right)$ present in vascular smooth muscle and helps with short-term control of arterial blood pressure under conditions of hemorrhage or sepsis, but this process requires of high circulating concentrations of vasopressin that depletes the stores within 1-h under conditions of profound baroreflex stimulation (54, 66). Interestingly, vasopressin concentrations required for its antidiuretic effect are much lower and still effective under conditions of shock (66).

\section{TREATMENT}

The most important step to treat refractory hypotension is to determine the primary cause(s). These include two main reasons, hypovolemia and/or sepsis, and within them the whole spectrum of possibilities, from blood loss, dehydration, sympathetic inactivity or inability to respond, metabolic acidosis, and endotoxemia. Sepsis however, is the most common cause of refractory hypotension due to the vasodilatory effects that result from it $(42,43,54)$. The aim of treatment is to overcome the vasodilation that results in hypotension, which is common to classes III ( $>30-40 \%$ blood loss) and IV (> $40 \%$ ) of shock (44). An algorithm is provided (Figure 2) to help in the decision process during treatment, with an emphasis on short-term control by manipulation of the factors that influence cardiac output and arterial blood pressure, including vascular resistance and compliance, contractility, heart rate and blood volume.

Monitoring of cardiovascular function to assess the condition of the patient and response to treatment is primordial. Arterial blood pressure is readily monitored by non-invasive methods; unfortunately they are inaccurate and unreliable in hypotensive patients (73). Direct arterial blood pressure monitoring is often pursued in critical patients, especially if under general anesthesia, and provides accurate values that can be continuously monitored to assess the effectiveness of fluid therapy when used with dynamic cardiovascular variables such as pulse pressure variation, stroke volume variation and systolic pressure variation, to better define fluid- responsive from non-responsive patients (see chapter "What are the most effective methods for monitoring IV fluid therapy?"). 


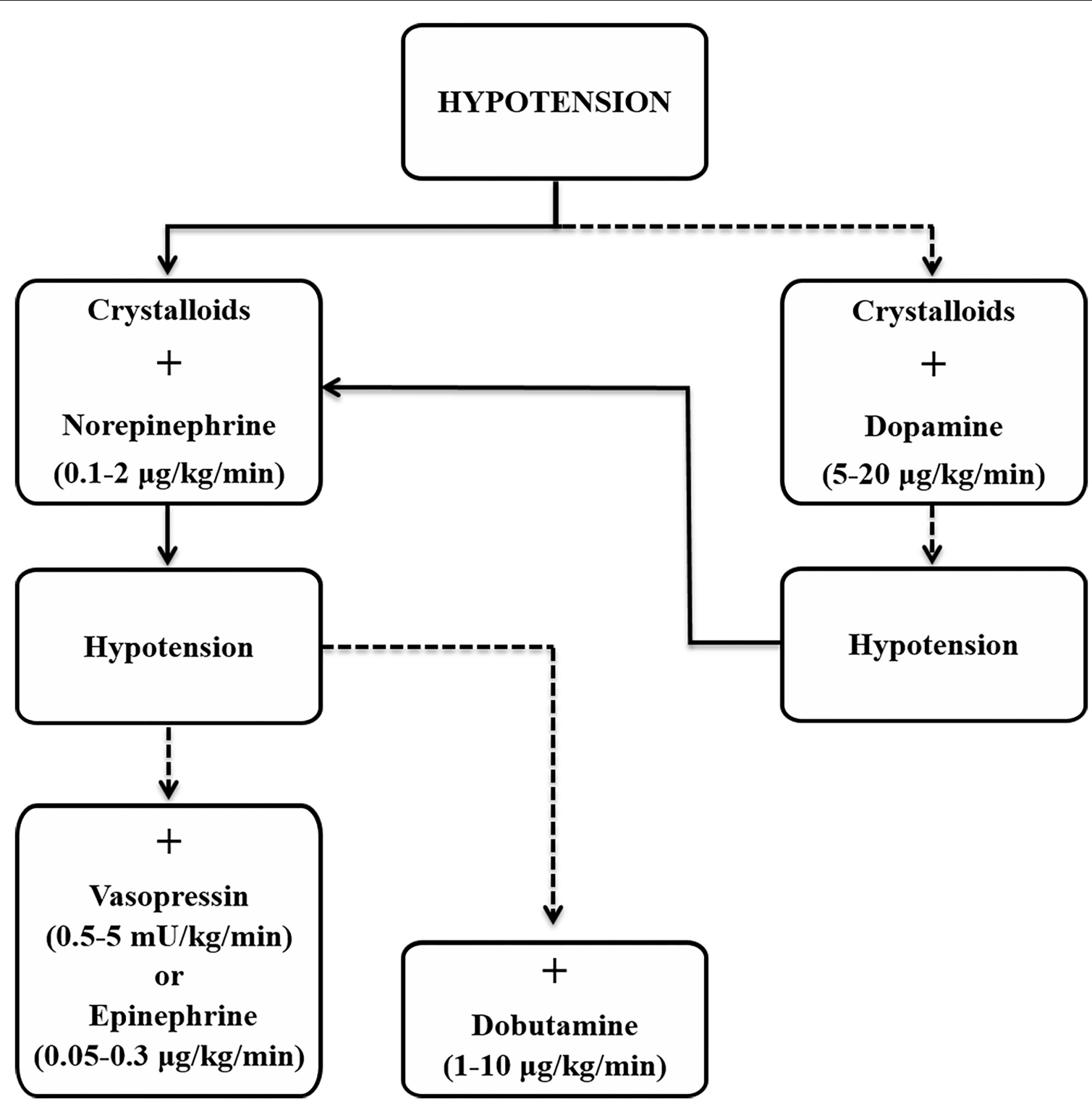

FIGURE 2 | Suggested approach for the treatment of hypotension based on current guidelines for management of sepsis and septic shock (72). Solid line, strong and preferred recommendation; dashed line, weaker recommendation.

\section{Vasopressors}

This review starts with vasopressors as the first line of therapy since the basic pathology is the decrease in vascular resistance. However, a combination of at least vasopressors and fluids should be instituted simultaneously for better success in improving arterial blood pressure. The most recent guidelines for management of sepsis and septic shock in people, from 2016, recommends an initial target mean arterial pressure of $65 \mathrm{mmHg}$ in patients with septic shock requiring vasopressors (72).

Vasopressor therapy aims at improving tissue perfusion through vasoconstriction and improved contractility. Norepinephrine, dopamine, epinephrine and phenylephrine are catecholamines used for their vasoconstrictor actions through the alpha-1 receptor, and inotropic actions through the beta-1 receptor, except for phenylephrine that lacks the latter. Arginine vasopressin (vasopressin) is also used for its vasoconstrictor effects, through its $\mathrm{V}_{\text {la }}$ receptor action.

Vasoconstrictor actions of alpha-adrenergic drugs on the alpha-1 receptor and of vasopressin on the $\mathrm{V}_{1 \text { a }}$ receptor are linked to G-protein-coupled receptors that result in smooth muscle contraction. Attachment of these agonists to the respective receptors triggers the stimulation of phospholipase $\mathrm{C}$, which generates the production of inositol triphosphate $\left(\mathrm{IP}_{3}\right)$ and diacylglycerol (DAG). These two substances interact between them to promote smooth muscle contraction; $\mathrm{IP}_{3}$ diffuses into the cell to act on an $\mathrm{IP}_{3}$-sensitive $\mathrm{Ca}^{2+}$ channel on the surface of 
the endoplasmic reticulum, facilitating the release of $\mathrm{Ca}^{2+}$ into the cytoplasm, which stimulates the calmodulin (CM) pathway by forming a $\mathrm{Ca}^{2+}{ }_{-} \mathrm{CM}$ complex that activates the myosin lightchain kinase and with the presence of ATP, it phosphorylates the myosin light chain and causes vasoconstriction (54). DAG remains in the cell membrane and stimulates the influx of $\mathrm{Ca}^{2+}$ into the cytoplasm through a $\mathrm{Ca}^{2+}$ channel; this additional $\mathrm{Ca}^{2+}$ with the $\mathrm{Ca}^{2+}$ released by the actions of $\mathrm{IP}_{3}$ also stimulates the CM pathway. In addition, the $\mathrm{Ca}^{2+}$ from DAG's actions stimulates the janus kinase 2 (JAK2) pathway, responsible for activating rho kinase, which prevents smooth muscle relaxation from occurring by inhibiting the myosin light chain phosphatase, as well as helps release reactive oxygen species, which are useful in increasing the sensitivity to $\mathrm{Ca}^{2+}$ and leads to additional stimulation of rho kinase (54).

Inotropic actions of beta-adrenergic drugs on the beta- 1 receptor are also linked to G-protein-coupled receptors that trigger the stimulation of adenylyl cyclase to generate the production of CAMP and activates protein kinase A (PKA), which activates L-type $\mathrm{Ca}^{2+}$ channels, phospholamban, sarcoplasmic reticulum ryanodine receptor channels (SR), cardiac troponin I (cTnI) and myosin binding protein (MyBP-C) $(74,75)$. Phospholamban phosphorylation removes its inhibitory effect on SR $\mathrm{Ca}^{2+}$ uptake and increases L-type $\mathrm{Ca}^{2+}$ current and SR $\mathrm{Ca}^{2+}$ cycling to allow for positive inotropic effects, with the contribution of PKA-dependent cTnI phosphorylation (74).

Patients with refractory hypotension under general anesthesia should be supported for contractility through beta-adrenergic inotropic effects because of the vasodilation from inhalant anesthetics and their negative dose-dependent effects on contractility $(47,53)$. Ideally, a drug with alpha- 1 and beta1 effects should be used to improve both arterial blood pressure and cardiac output, but not at the expense of excessive vasoconstriction that may negatively affect cardiac output. For example, increasing mean arterial pressure to $85 \mathrm{mmHg}$ in patients with septic shock did not improve renal values and metabolic markers (lactate, oxygen consumption) from those already achieved at $65 \mathrm{mmHg}(36)$.

The guidelines for management of sepsis and septic shock have published recommendations on the different types of vasopressors that should be used for resuscitation upon reviewing the literature; the higher the quality of evidence, the more likely a strong recommendation is issued (72). According to the guidelines, norepinephrine is strongly recommended/moderate quality of evidence as the first line-drug (72). Norepinephrine, through its alpha- and beta- 1 adrenergic actions, can increase blood pressure and cardiac output (26).

Vasopressin has been considered the second line-drug due to its catecholamine-sparing properties $(40,54)$. The vasoconstriction and increase in vascular resistance caused by vasopressin can decrease cardiac output (26), and the recent guidelines recommend adding either vasopressin (weak recommendation/moderate quality of evidence) or epinephrine (weak recommendation/low quality of evidence) to norepinephrine to reach the target mean arterial pressure, or adding vasopressin (weak recommendation/moderate quality of evidence) to decrease the norepinephrine dose (72).
Vasopressin due to its actions on $\mathrm{V}_{1 \mathrm{a}}$ receptor does not result in arrhythmias and can increase systemic arterial blood pressure even in the presence of acidemia (76) and has been recommended in refractory shock due to a relative vasopressin deficiency and to benefit from a norepinephrine-sparing effect $(40,77)$. However, vasopressin can compromise splanchnic and peripheral tissue perfusion under conditions of hypovolemia and these negative effects should be considered (76).

Other catecholamines have been used according to availability, but both norepinephrine and the non-catecholamine vasopressin are considered superior $(40,72)$. Epinephrine delays normalization of arterial $\mathrm{pH}$ and lactate concentrations from exaggerated aerobic glycolysis through $\mathrm{Na}^{+} \mathrm{K}^{+}$ATPase stimulation within the muscles, which may interfere with interpretation of a patient's proper responsiveness to treatment and is likely to indicate anaerobic metabolism $(78,79)$. The current guidelines for management of sepsis and septic shock do not state a specific recommendation for epinephrine on its own, but added to norepinephrine, despite no difference in mortality rate when compared to norepinephrine, although adverse drug-related events were more common with epinephrine (72). In the previous guidelines from 2012, a weak recommendation / moderate quality of evidence was issued for epinephrine (80).

Dopamine is less efficient at normalizing arterial blood pressure than norepinephrine and it has been associated with arrhythmias than norepinephrine (42), most likely because vasoconstrictor effects of dopamine are achieved with higher infusion rates, which also exacerbate beta- 1 adrenergic effects (81). In addition, mortality is higher than in patients receiving norepinephrine (42). Dopamine is recommended by the guidelines for management of sepsis and septic shock as an alternative vasopressor to norepinephrine only in highly selected patients (e.g., low risk of tachyarrhythmias and absolute or relative bradycardia) with a weak recommendation / low quality of evidence (72). There is also a strong recommendation/high quality of evidence against the use of low-dose dopamine for renal protection (72).

Phenylephrine is a pure alpha-1 agonist; therefore only vasoconstriction is expected from it, which may be detrimental in hypovolemic patients that also exhibit a reduction in cardiac output, unless contractility is supported with beta-1 agonists (81). Septic patients treated with phenylephrine had a higher mortality rate than patients treated with norepinephrine (82) and current recommendations from the guidelines for management of sepsis and septic shock state that phenylephrine use should be limited until more research is available (72).

Higher doses of catecholamines and/or vasopressin are usually required in refractory hypotension from a decreased response to endogenous or exogenous vasoactive substances such as angiotensin II and vasopressors (83). Tachyphylaxis occurs with high doses and repetitive exposure to alpha-adrenergic drugs, because the alpha-1 receptors are desensitized and internalized (84).

The use of higher doses results in a higher incidence of adverse effects, including arrhythmias $(42,79)$. In attempts to modulate individual effects and reduce adverse effects, norepinephrine has also been combined with dobutamine $(78,79)$. Dobutamine 
increases cardiac output through its beta-1 adrenergic effects (inotropy), which increases arterial blood pressure under ideal conditions of vascular tone since it lacks alpha-adrenergic effects (26). The guidelines for management of sepsis and septic shock suggest using dobutamine in patients who show evidence of persistent hypoperfusion despite adequate fluid loading and the use of vasopressor drugs, under a weak recommendation/low quality of evidence (72).

Terlipressin is a prodrug to its metabolite lysine vasopressin; both are more selective and have a longer action than vasopressin for the $V_{1}$ receptor for the specific vasoconstrictor effects, but its use is still under investigation for refractory hypotension $(40,54)$. Selepressin is another $V_{1}$ receptor agonist with a short duration of action, that has demonstrated positive effects in cardiovascular variables and fluid balance to prevent lung edema in an ovine model of septic shock (85) and is currently undergoing investigation.

Standard doses of sympathomimetics and vasopressin used to treat hypotension include $1-10 \mu \mathrm{g} / \mathrm{kg} / \mathrm{min}$ for dopamine, 1-10 $\mu \mathrm{g} / \mathrm{kg} / \mathrm{min}$ for dobutamine, $0.1-2 \mu \mathrm{g} / \mathrm{kg} / \mathrm{min}$ for norepinephrine, $0.05-0.1 \mu \mathrm{g} / \mathrm{kg} / \mathrm{min}$ for epinephrine, $0.5-2$ $\mu \mathrm{g} / \mathrm{kg} / \mathrm{min}$ for phenylephrine, and $0.3-5 \mathrm{mU} / \mathrm{kg} / \mathrm{min}$ for vasopressin (81). In human patients with refractory hypotension, higher doses than those mentioned above for each of these drugs are often necessary in attempts to manage their cardiovascular derangement $(41,42,86)$; from a prognostic point of view, the need for higher doses of vasopressors is associated with unfavorable outcomes $(41,86)$.

\section{Fluid Therapy}

Isotonic crystalloids are recommended as the initial fluid of choice for shock reversal in septic patients, since the time to reach preset values of mean arterial pressure, central venous oxygen saturation, normalization of lactate levels and discontinuation of vasopressors, was achieved as quickly as in patients resuscitated with a combination of synthetic colloids (hydroxyethyl starch or gelatin) and crystalloids (32, 72, 87, 88 ). One disadvantage of synthetic colloids is that despite their volume expansion/retention properties, often result in higher incidence of impaired renal function than crystalloids and required volumes of resuscitation are only marginally lower than for crystalloids (32). In addition, using starches, dextrans, albumin, fresh frozen plasma, or gelatins $v$ s. crystalloids makes little or no difference in mortality of critically ill patients (87, 88). Isotonic crystalloids also resulted in similar outcomes when compared to hypertonic crystalloids (88).

The guidelines for management of sepsis and septic shock in people recommends fluids as follows: a strong recommendation/moderate quality of evidence for crystalloids; a weak recommendation/low quality evidence for use of either balanced crystalloids or saline; a weak recommendation/low quality of evidence for albumin in addition to crystalloids; a strong recommendation/high quality of evidence against hydroxyethyl starches; and a weak recommendation/low quality of evidence for crystalloids over gelatins (72).

Studies in normovolemic and normotensive dogs, maintained at useful clinical inhalant anesthetic concentrations to allow surgery (1.1-1.25 MAC), arterial blood pressure values and the effects on packed cell volume and total protein were similar in groups receiving no fluid therapy or up to $20 \mathrm{~mL} / \mathrm{kg} / \mathrm{h}$ of isotonic crystalloids $(24,25)$, because fluid balance dynamics and cardiovascular function are well-preserved in those conditions of light anesthetic planes $(89,90)$.

In hypotensive models using healthy research dogs that were normovolemic and maintained at a systolic arterial blood pressure of $80 \mathrm{mmHg}$ with a deep level of isoflurane anesthesia [3.1-3.4\% end-tidal (2.4-2.8 MAC)], isotonic crystalloids, at fast and high volume infusion rates used for shock of $80 \mathrm{~mL} / \mathrm{kg}$ for up to 1-h did not improve blood pressure, whereas the colloid hetastarch administered at a rate of $80 \mathrm{~mL} / \mathrm{kg} / \mathrm{h}$ to maximum volume $40 \mathrm{~mL} / \mathrm{kg}$, restored systolic pressures to within $10 \%$ of baseline values predetermined at $1.6-1.7 \%(1.3 \mathrm{MAC})$ in $66 \%$ of cases (22). In a similar study, research dogs maintained also at 3\% (2.3 MAC), arterial blood pressure did not improve with the administration of isotonic crystalloids also infused at a high volume rate of $60 \mathrm{~mL} / \mathrm{kg} / \mathrm{h}$ for $45 \mathrm{~min}$, until the depth of anesthesia was decreased to $1.6 \%$ while the fluid rate continued for another $15 \mathrm{~min}$ (23).

Normovolemic patients that exhibit hypotension under general inhalant anesthesia do not have increases in arterial blood pressure with high volume fluid rates of isotonic crystalloids, and are also less responsive to colloids, because the infused volume results in a decrease in systemic vascular resistance $(22,23)$. Despite the hypotension, cardiac output, lactate, venous and arterial $\mathrm{pH}$, and mixed venous oxygen saturation remained within acceptable levels and arterial blood pressure did not decrease any further in these research models $(22,23)$. According to Ohm's law ( $\left.\mathrm{ABP}=\mathrm{CO}{ }^{\mathrm{x}} \mathrm{VR}\right)$, arterial blood pressure was maintained as a result of an improvement in cardiac output from the expansion in blood and plasma volume $(22,23)$. Interestingly, with crystalloid administration and under the conditions of deep anesthesia, heart rate and stroke volume did not change in both studies $(22,23)$. Since cardiac output is also the product of both $\left(\mathrm{CO}=\mathrm{HR}^{\mathrm{x}} \mathrm{SV}\right)$, an increase in myocardial contractility is likely responsible for the improvement in cardiac output, as a result of the expanded circulating volume that decreases viscosity from hemodilution of the packed cell volume and total protein, which in association with the lower vascular resistance facilitates the work of the heart, even if arterial blood pressure does not change $(22,23)$. In this regard, the guidelines for management of sepsis and septic shock only recommend (strong recommendation/high quality of evidence) red blood cell transfusion if the hemoglobin concentration decreases to $<7.0 \mathrm{~g} / \mathrm{dL}$ in the absence of extenuating circumstances, such as myocardial ischemia, severe hypoxemia, or acute hemorrhage (72).

Findings from healthy research dogs should be extrapolated cautiously to patients that suffer from refractory hypotension and shock. The expectations and benefits of fluid therapy in normalizing arterial blood pressure differ in normovolemic $v s$. hypovolemic patients. The effects of anesthetic drugs and depth of anesthesia should also be considered. Hypovolemic, septic patients exhibit refractory hypotension and low cardiac output, resulting in long lasting hypotension and severely compromised tissue perfusion that may become irreversible. 
The benefit of fluid therapy in reestablishing cardiovascular variables in hypovolemic septic patients is limited without vasopressors. The use of vasopressors should always accompany fast and high volume rates of isotonic crystalloids in these patients, and should include frequent monitoring for hemodilution and decreases in colloid oncotic pressure, because these patients are likely to have impaired oxygen content and delivery, altered fluid transmembrane dynamics and predisposition to edema, all of which affect tissue integrity (91). The most recent guidelines for management of sepsis and septic shock strongly recommends/low quality of evidence that at least $30 \mathrm{~mL} / \mathrm{kg}$ of IV isotonic fluids be given within the first $3 \mathrm{~h}$ and that frequent reassessment of cardiovascular variables (heart rate, blood pressure, arterial oxygen saturation, respiratory rate, temperature, urine output, and others as available) (72).

\section{Other Drugs}

\section{Hydrocortisone}

Cortisol released by the hypothalamic-pituitary-adrenal axis is important in mediating vasoconstriction through regulation of vascular smooth muscle sensitivity to the endogenous catecholamines norepinephrine and epinephrine and the hormone angiotensin II, and through regulation of cytokines. Mechanisms involved in restoring vascular tone include an increase in alpha-adrenergic receptor gene expression (92); inhibition of the arachidonic acid cascade $(93,94)$, preventing prostacyclin formation and its vasodilatory effects (67); genomic inhibition of the nuclear translocation of the transcription factor NF- $\mathrm{kB}$, responsible for expression of pro-inflammatory genes for cytokines and chemokines (95); and inhibition of expression of inducible nitric oxide synthase from endothelial cells, halting nitric oxide production and inhibiting vasodilation $(96,97)$. Hydrocortisone provides both glucocorticoid and mineralocorticoid coverage.

The current guidelines for management of sepsis and septic shock suggests against the use of IV hydrocortisone to treat septic shock patients if adequate fluid resuscitation and vasopressor therapy are able to restore hemodynamic stability. If this is not achievable, IV hydrocortisone at a dose of $200 \mathrm{mg}$ per day is suggested (weak recommendation/low quality of evidence) (72).

In patients receiving corticosteroid therapy for chronic autoimmune or inflammatory diseases and in patients receiving replacement therapy because of chronic primary or secondary adrenal insufficiency, it is important that they continue receiving their current dose of corticosteroids to maintain cardiovascular function, especially if general anesthesia is planned. If the patient exhibits refractory hypotension, supplemental hydrocortisone therapy should be considered.

\section{Angiotensin II}

Angiotensin II has been recommended due to its actions on the AT1 receptor, a G-protein-coupled receptor, and stimulates the same transduction pathways as vasopressors through activation of phospholipase $\mathrm{C}$ for the generation of $\mathrm{IP}_{3}$ and $\mathrm{DAG}$ and stimulation of the JAK2 pathway (21), all of which result in vasoconstriction, aldosterone secretion and vasopressin release (40).
Angiotensin II was evaluated in a double blind, randomized, controlled trial in patients with vasodilatory shock that were not responsive to high doses of vasopressors (98). In this study, patients receiving angiotensin II in combination with the vasopressor had lower requirements for vasopressors, including norepinephrine, and a higher mean arterial blood pressure than the placebo group receiving only the vasopressor; however, mortality rate and adverse effects were similar between the two groups (98). The dose used in this study for angiotensin II was 20 $\mathrm{ng} / \mathrm{kg} / \mathrm{min}$ for the first $3 \mathrm{~h}$, and it was lowered in many instances due to an improvement in the mean arterial blood pressure (98).

Angiotensin II is not mentioned in the most current guidelines for management of sepsis and septic shock (72) because the study by Khanna et al. (98) is contemporary and was not available.

\section{Methylene Blue}

Methylene blue inhibits nitric oxide synthase, preventing the production of nitric oxide and cGMP, therefore vasodilation does not occur (99). In vitro, methylene blue also suppresses the production and release of prostacyclin, in both the presence and absence of pro-inflammatory cytokines, in dog renal artery smooth muscle cells, which may also contribute to prevent vasodilation by inhibiting the formation of c-AMP, which normally would prevent cytoplasmic $\mathrm{Ca}^{2+}$ from causing vasoconstriction (100).

Methylene blue has been used successfully at decreasing mortality in vasodilatory shock after cardiopulmonary bypass at IV doses of $1-2 \mathrm{mg} / \mathrm{kg}$ to counteract refractory hypotension that requires of high inotropic support (99). However, its use in vasodilatory shock due to sepsis is not yet established and is not mentioned in the current guidelines for management of sepsis and septic shock (72).

\section{Alpha-2 Agonists}

Sedation is often required in human septic patients. Dexmedetomidine has been used for this purpose and spiked interest due to its central and peripheral actions on sympathetic activity and vascular tone. Dexmedetomidine causes vasoconstriction and an increase in mean arterial pressure through its post-synaptic alpha-1 and-2 adrenergic actions, but it can be used also as an antihypertensive drug due to its presynaptic alpha- 2 actions that induce a negative feedback on norepinephrine secretion, which causes hypotension (101). However, in rats induced to septic shock, dexmedetomidine administration increased the response to exogenous norepinephrine (102), indicating that it restores the responsiveness to alpha- 1 agonists.

In human patients with septic shock and initially maintained sedated with propofol and remifentanil, while receiving norepinephrine to maintain adequate mean arterial blood pressures, had higher norepinephrine requirements than when dexmedetomidine was used to replace the propofol, and norepinephrine requirements increased again when sedation was switched back to propofol (103).

The use of dexmedetomidine is not mentioned in the current guidelines for management of sepsis and septic shock (72). 
In summary, refractory hypotension should be addressed aggressively to reestablish arterial blood pressure control and blood flow to tissues/organs. Therapeutic actions include fluid therapy with the use of sympathomimetics and vasopressors that help overcome or at least minimize the ongoing state of vasoplegia, In anesthetized patients, the vasodilatory effects of inhalant anesthetics contribute to the hypotension and anesthesia

\section{REFERENCES}

1. Haskins SC. Monitoring anesthetized patients. In: Grimm KA, Lamont LA, Tranquilli WJ, Greene SA, Robertson SA, editors. Veterinary Anesthesia and Analgesia. The Fifth Edition of Lumb and Jones. Ames, IO: Wiley (2015). p. 86-113. doi: 10.1002/9781119421375.ch4

2. Klabunde RE. Cardiovascular Physiology Concepts. Philadelphia, PA: Lippincott Williams \& Wilkins (2012).

3. Chalifoux A, Dallaire A, Blais D, Larivière N, Pelletier N. Evaluation of the arterial blood pressure of dogs by two noninvasive methods. Can J Comp Med. (1985) 49:419-23.

4. Haskins S, Pascoe PJ, Ilkiw JE, Fudge J, Hopper K, Aldrich J. Reference cardiopulmonary values in normal dogs. Comp Med. (2005) 55:156-61.

5. Dyson DH, Allen DG, Ingwersen W, Pascoe PJ, O'Grady M. Effects of Saffan on cardiopulmonary function in healthy cats. Can J Vet Res. (1987) 51:236-9.

6. Ingwersen W, Allen DG, Dyson DH, Pascoe PJ, O'Grady MR. Cardiopulmonary effects of a ketamine hydrochloride/acepromazine combination in healthy cats. Can J Vet Res. (1988) 52:1-4.

7. Slingerland LI, Robben JH, Shaafsma I, Kooistra HS. Response of cats to familiar and unfamiliar human contact using continuous direct arterial blood pressure measurement. Res Vet Sci. (2008) 85:575-82. doi: 10.1016/j.rvsc.2007.12.008

8. Akkerdaas LC, Mioch P, Sap R, Hellebrekers LJ. Cardiopulmonary effects of three differente anaesthesia protocols in cats. Vet Quart. (2001) 23:182-6. doi: 10.1080/01652176.2001.9695109

9. Solano AM, Valverde A, Desrochers A, Nykamp S, Boure LP. Behavioural and cardiorespiratory effects of a constant rate infusion of medetomidine and morphine for sedation during standing laparoscopy in horses. Equine Vet J. (2009) 41:153-9. doi: 10.2746/042516408X342984

10. Tapio H, Raekallio MR, Mykkänen A, Männikkö S, Scheinin M, Bennett RC, et al. Effects of vatinoxan on cardiorespiratory function and gastrointestinal motility during constant-rate medetomidine infusion in standing horses. Equine Vet J. (2019) 51:646-52. doi: 10.1111/evj.13085

11. Valverde A, Doherty T. Anesthesia and analgesia of ruminants. In: Fish R, Danneman PJ, Brown M, Karas A, editors. Anesthesia and Analgesia in Laboratory Animals, 2nd Edition. San Diego, CA: Academic Press (2008). p. 385-412. doi: 10.1016/B978-012373898-1.50018-8

12. Ichikawa S, Johnson JA, Fowler WL, Payne CG, Kurz K, Keitzer WF. Pressor responses to norepinephrine in rabbits with 3-day and 30-day renal artery stenosis. The role of angiotensin IICirc Res. (1978) 43:437-46. doi: 10.1161/01.RES.43.3.437

13. van den Buuse M, Malpas SC. 24-hour recordings of blood pressure, heart rate and behavioural activity in rabbits by radio telemetry: effects of feeding and hypotension. Physiol Behav. (1997) 62:83-9. doi: 10.1016/S0031-9384(97)00145-5

14. Clow KA, Giraud GD, Ogden BE, Brooks VL. Pregnancy alters hemodynamic responses to hemorhage in conscious rabbits. Am J Physiol Heart Circ Physiol. (2003) 284:H1110-8. doi: 10.1152/ajpheart.00626.2002

15. Lim K, Burke SL, Armitage JA, Head GA. Comparison of blood pressure and sympathetic activity of rabbits in their home cage and the laboratory environment. Exp Physiol. (2012) 97:1263-72. doi: 10.1113/expphysiol.2012.064972

16. Bijker JB, van Klei WA, Kappen $\mathrm{TH}$, van Wolfswinkel L, Moons KGM, Kalkman CJ. Incidence of intraoperative hypotension as a function of the chosen definition. Anesthesiology. (2007) 107:213-20. doi: 10.1097/01.anes.0000270724.40897.8e time should be reduced if at all possible, as well as consider the use of balanced techniques that could help avoid excessive inhibition of sympathetic activity.

\section{AUTHOR CONTRIBUTIONS}

AV: manuscript writing.
17. Walsh M, Devereaux PJ, Garg AX, Kurz A, Turan A, Rodseth RN, et al. Relationship between intraoperative mean arterial pressure and clinical outcomes after noncardiac surgery. Anesthesiology. (2013) 119:507-15. doi: 10.1097/ALN.0b013e3182a10e26

18. Wesselink EM, Kappen TH, Torn HM, Slooter AJC, van Klei WA. Intraoperative hypotension and the risk of postoperative adverse outcomes: a systematic review. Br J Anaesth. (2018) 121:706-21. doi: 10.1016/j.bja.2018.04.036

19. Nafiu OO, Voepel-Lewis T, Morris M, Chimbira WT, Malviya S, Reynolds PI, et al. How do pediatric anesthesiologists define intraoperative hypotension? Paediatr Anaesth. (2009) 19:1048-53. doi: 10.1111/j.1460-9592.2009.03140.x

20. Guyton AC. The relationship of cardiac output and arterial pressure control. Circulation. (1981) 64:1079-88. doi: 10.1161/01.CIR.64.6.1079

21. Guo DF, Sun YL, Hamet P, Inagami T. The angiotensin II type 1 receptor and receptor-associated proteins. Cell Res. (2001) 11:165-80. doi: 10.1038/sj.cr.7290083

22. Aarnes TK, Bednarski RM, Lerche P, Hubbell JA, Muir WW. Effect of intravenous administration of lactated Ringer's solution or hetastarch for the treatment of isoflurane-induced hypotension in dogs. Am J Vet Res. (2009) 70:1345-53. doi: 10.2460/ajvr.70.11.1345

23. Valverde A, Gianotti G, Rioja E, Hathway E. Effects of high-volume and rapid-fluid therapy on cardiovascular function and hematological values during isoflurane-induced hypotension in healthy dogs. Can J Vet Res. (2012) 76:99-108.

24. Gaynor JS, Wertz EM, Kesel LM, Baker GE, Cecchini C, Rice K, et al. Effects of intravenous administration of fluids on packed cell volume, blood pressure, and total protein and blood glucose concentrations in healthy halothane-anesthetized dogs. J Am Vet Med Assoc. (1996) 208:2013-5.

25. Hauptman JG, Richter MA, Wood SL, Nachreiner RF. Effects of anesthesia, surgery, and intravenous administration of fluids on plasma antidiuretic hormone concentrations in healthy dogs. Am J Vet Res. (2000) 61:1273-6. doi: 10.2460/ajvr.2000.61.1273

26. Valverde A, Giguère S, Sanchez LC, Shih A, Ryan C. Effects of dobutamine, norepinephrine, and vasopressin on cardiovascular function in anesthetized neonatal foals with induced hypotension. Am J Vet Res. (2006) 67:1730-7. doi: 10.2460/ajvr.67.10.1730

27. Wiese AJ, Barter LS, Ilkiw JE, Kittleson MD, Pypendop BH. Cardiovascular and respiratory effects of incremental doses of dopamine and phenylephrine in the management of isoflurane-induced hypotension in cats with hypertrophic cardiomyopathy. Am J Vet Res. (2012) 73:908-16. doi: 10.2460/ajvr.73.6.908

28. Pascoe PJ, Ilkiw JE, Pypendop BH. Effects of increasing infusion rates of dopamine, dobutamine, epinephrine, and phenylephrine in healthy anesthetized cats. Am J Vet Res. (2006) 67:1491-9. doi: 10.2460/ajvr.67.9.1491

29. Craig CA, Haskins SC, Hildebrand SV. The cardiopulmonary effects of dobutamine and norpepinephrine in isoflurane-anesthetized foals. Vet Anaesth Analg. (2007) 34:377-87. doi: 10.1111/j.1467-2995.2006.00304.x

30. Lienhart A, Auroy Y, Pequignot F, Benhamou D, Warszawski J, Bovet M, et al. Survey of anesthesia-related mortality in France. Anesthesiology. (2006) 105:1087-97. doi: 10.1097/00000542-200612000-00008

31. Salmasi V, Maheshwari K, Yang D, Mascha EJ, Singh A, Sessler DI, et al. Relationship between intraoperative hypotension, defined by either reduction from baseline or absolute thresholds, and acute kidney and myocardial injury after noncardiac surgery: a retrospective cohort analysis. Anesthesiology. (2017) 126:47-65. doi: 10.1097/ALN.0000000000001432 
32. Bayer O, Reinhart K, Kohl M, Kabisch B, Marshall J, Sakr Y, et al. Effects of fluid resuscitation with synthetic colloids or crystalloids alone on shock reversal, fluid balance, and patient outcomes in patients with severe sepsis: a prospective sequential analysis. Crit Care Med. (2012) 40:2543-51. doi: 10.1097/CCM.0b013e318258fee7

33. Sun LY, Wijeysundera DN, Tait GA, Beattie WS. Association of intraoperative hypotension with acute kidney injury after elective noncardiac surgery. Anesthesiology. (2015) 123:515-23. doi: 10.1097/ALN.0000000000000765

34. Maheshwari K, Turan A, Mao G, Yang D, Niazi AK, Agarwal D, et al. The association of hypotension during non-cardiac surgery, before and after skin incision, with postoperative acute kidney injury: a retrospective cohort analysis. Anaesthesia. (2018) 73:1223-8. doi: 10.1111/anae.14416

35. Monk TG, Saini V, Weldon BC, Sigl JC. Anesthetic management and oneyear mortality after noncardiac surgery. Anesth Analg. (2005) 100:4-10. doi: 10.1213/01.ANE.0000147519.82841.5E

36. Bourgoin A, Leone M, Delmas A, Garnier F, Albanèse J, Martin C. Increasing mean arterial pressure in patients with septic shock: effects on oxygen variables and renal function. Crit Care Med. (2005) 33:780-6. doi: 10.1097/01.CCM.0000157788.20591.23

37. Boström I, Nyman G, Kampa N, Häggström J, Lord P. Effects of acepromazine on renal function in anesthetized dogs. Am J Vet Res. (2003) 64:590-8. doi: 10.2460/ajvr.2003.64.590

38. Coonan TJ, Hope CE. Cardio-respiratory effects of change of body position. Can Anaesth Soc J. (1983) 30:424-37. doi: 10.1007/BF03007869

39. Kirchheim HR, Ehmke H, Hackenthal E, Löwe W, Persson P. Autoregulation of renal blood flow, glomerular filtration rate and renin release in conscious dogs. Pflügers Arch. (1987) 410:441-9. doi: 10.1007/BF00586523

40. Levy B, Fritz C, Tahon E, Jacquot A, Auchet T, Kimmoun A. Vasoplegia treatments: the past, the present, and the future. Crit Care. (2018) 22:52. doi: 10.1186/s13054-018-1967-3

41. Bassi E, Park M, Pontes Azevedo LC. Therapeutic strategies for highdose vasopressor-dependent shock. Crit Care Res Pract. (2013) 2013:654708. doi: $10.1155 / 2013 / 654708$

42. De Backer D, Biston P, Devriendt J, Madl C, Chochrad D, Aldecoa C, et al. Comparison of dopamine and norepinephrine in the treatment of shock. $N$ Engl J Med. (2010) 362:779-89. doi: 10.1056/NEJMoa0907118

43. Singer M, Deutschman CS, Seymour CW, Shankar-Hari M, Annane $\mathrm{D}$, Bauer $\mathrm{M}$, et al. The third international consensus definitions for sepsis and septic shock (Sepsis-3). J Am Med Assoc. (2016) 315:801-10. doi: 10.1001/jama.2016.0287

44. Mutschler M, Paffrath T, Wölfl C, Probst C, Nienaber U, Schipper IB, et al. The ATLS ${ }^{\circledR}$ classification of hypovolaemic shock: a well established teaching tool on the edge? Injury. (2014) 45(suppl. 3):S35-8. doi: 10.1016/j.injury.2014.08.015

45. Wamberg S, Sandgaard NCV, Bie P. Simultaneous determination of total body water and plasma volume in conscious dogs by the indicator dilution principle. J Nutr. (2002) 132:1711S-3. doi: 10.1093/jn/132.6.1 $711 \mathrm{~S}$

46. Carroll RG, Iams SG, Pryor WH, Allison EJ. Single hemorrhage: a clinically relevant canine model of hemorrhagic shock. Resuscitation. (1988) 16:11926. doi: 10.1016/0300-9572(88)90076-7

47. Muzi M, Ebert TJ. A comparison of baroreflex sensitivity during isoflurane and desflurane anesthesia in humans. Anesthesiology. (1995) 82:919-25. doi: 10.1097/00000542-199504000-00015

48. Nagasaki G, Tanaka M, Nishikawa T. The recovery profile of baroreflex control of heart rate after isoflurane or sevoflurane anesthesia in humans. Anesth Analg. (2001) 83:1127-31. doi: 10.1097/00000539-200111000-00012

49. Sato M, Tanaka M, Umehara S, Nishikawa T. Baroreflex control of heart rate during and after propofol infusion in humans. Br J Anaesth. (2005) 94:577-81. doi: 10.1093/bja/aei092

50. Mattson SF, Kerr CL, Dyson DH, Mirakhur KK. The effect of hypovolemia due to hemorrhage on the minimum alveolar concentration of isoflurane in the dog. Vet Anaesth Analg. (2006) 33:296-301. doi: 10.1111/j.1467-2995.2005.00273.x

51. Klein AV, Teixeira-Neto FJ, Garofalo NA, Lagos-Carvajal AP, Diniz MS, Becerra-Velázquez DR. Changes in pulse pressure variation and plethysmographic variability index caused by hypotension-inducing hemorrhage followed by volume replacement in isoflurane-anesthetized dogs. Am J Vet Res. (2016) 77:280-7. doi: 10.2460/ajvr.77.3.280

52. Diniz MS, Teixeira-Neto FJ, Celeita-Rodríguez N, Girotto CH, Fonseca MW, Oliveira-Garcia AC, et al. Effects of 6\% tetrastarch and lactated Ringer's solution on extravascular lung water and markers of acute renal injury in hemorrhaged, isoflurane-anesthetized healthy dogs. J Vet Intern Med. (2018) 32:712-21. doi: 10.1111/jvim.14853

53. Kazama T, Ikeda K. The comparative cardiovascular effects of sevoflurane with halothane and isoflurane. J Anesth. (1988) 2:63-8. doi: 10.1007/s0054080020063

54. Chow JH, Abuelksem E, Sankova S, Henderson RA, Mazzeffi MA, Tanaka KA. Reversal of vasodilatory shock: current perspectives on conventional, rescue, and emerging vasoactive agents for the treatment of shock. Anesth Analg. (2020) 130:15-30. doi: 10.1213/ANE.0000000000004343

55. Gayle JM, Cohen ND, Chaffin MK. Factors associated with survival in septicemic foals: 65 cases (1988-1995). J Vet Inter Med. (1998) 12:140-6. doi: 10.1111/j.1939-1676.1998.tb02109.x

56. Corley KTT, Donaldson LL, Furr MO. Arterial lactate concentration, hospital survival, sepsis and SIRS in critically ill neonatal foals. Equine Vet J. (2005) 37:53-9. doi: 10.2746/0425164054406856

57. Dayer T, Howard J, Spreng D. Septic peritonitis from pyloric and non-pyloric gastrointestinal perforation: prognostic factors in 44 dogs and 11 cats. J Small Anim Pract. (2013) 54:625-9. doi: 10.1111/jsap.12151

58. Isola JGMP, Santana AE, Pereira-Neto GB, Rabelo RC. Severe sepsis and septic shock survival in a clinical canine model. Crit Care. (2013) 17(Suppl. 4):P110. doi: 10.1186/cc13009

59. Bentley AM, Mayhew PD, Culp WTN, Otto CM. Alterations in the hemostatic profiles of dogs with naturally occurring septic peritonitis. J Vet Emerg Crit Care. (2013) 23:14-22. doi: 10.1111/vec.12013

60. Cortellini S, Seth M, Kellett-Gregory LM. Plasma lactate concentrations in septic peritonitis: a retrospective study of 83 dogs (2007-2012). J Vet Emerg Crit Care. (2015) 25:388-95. doi: 10.1111/vec.12234

61. Weber EJ, Sanchez LC, Giguère S. Re-evaluation of the sepsis score in equine neonates. Equine Vet J. (2015) 47:275-8. doi: 10.1111/evj.12279

62. Viu J, Armengou L, Rios J, Cesarini C, Jose-Cunilleras E. Acid base imbalances in ill neonatal foals and their association with survival. Equine Vet J. (2017) 49:51-7. doi: 10.1111/evj.12542

63. Wong DM, Ruby RE, Dembek KA, Barr BS, Reuss SM, Magdesian KG, et al. Evaluation of updated sepsis scoring systems and systemic inflammatory response syndrome criteria and their association with sepsis in equine neonates. J Vet Intern Med. (2018) 32:1185-93. doi: 10.1111/jvim.15087

64. Martiny P, Goggs R. Biomarker guided diagnosis of septic peritonitis in dogs. Front Vet Sci. (2019) 6:208. doi: 10.3389/fvets.2019.00208

65. Xu LL, Warren MK, Rose WL, Gong W, Wang JM. Human recombinant monocyte chemotactic protein and other $\mathrm{C}-\mathrm{C}$ chemokines bind and induce directional migration of dendritic cells in vitro. J Leukocyte Biol. (1996) 60:365-71. doi: 10.1002/jlb.60.3.365

66. Landry DW, Oliver JA. The pathogenesis of vasodilatory shock. N Engl J Med. (2001) 345:588-95. doi: 10.1056/NEJMra002709

67. Levy B, Collin S, Sennoun N, Ducrocq N, Kimmoun A, Asfar P, et al. Vascular hyporesponsiveness to vasopressors in septic shock: from bench to bedside. Intensive Care Med. (2010) 36:2019-29. doi: 10.1007/s00134-010-2045-8

68. Wotman K, Wilkins PA, Palmer JE, Boston RC. Association of blood lactate concentration and outcome in foals. J Vet Intern Med. (2009) 23:598-605. doi: 10.1111/j.1939-1676.2009.0277.x

69. Tennent-Brown BS, Wilkins PA, Lindborg S, Russell G, Boston RC. Sequential plasma lactate concentrations as prognostic indicators in adult equine emergencies. J Vet Intern Med. (2010) 24:198-205. doi: 10.1111/j.1939-1676.2009.0419.x

70. Kimmoun A, Novy E, Auchet T, Ducrocq N, Levy B. Hemodynamic consequences of severe lactic acidosis in shock states: from bench to bedside. Crit Care. (2015) 19:175. doi: 10.1186/s13054-015-0896-7

71. Wang P, Zhou M, Cioffi WG, Bland KI, Ba ZF, Chaudry IH. Is prostacyclin responsible for producing the hyperdynamic response during early sepsis? Crit Care Med. (2000) 28:1534-9. doi: 10.1097/00003246-20000500 0-00046

72. Rhodes A, Evans LE, Alhazzani W, Levy MM, Antonelli M, Ferrer R, et al. Surviving sepsis campaign: international guidelines for management 
of sepsis and septic shock: 2016. Crit Care Med. (2017) 45:486-552. doi: 10.1097/CCM.0000000000002255

73. Skelding A, Valverde A. Review of non-invasive blood pressure measurement in veterinary species. Part two: evaluation of the performance of non-invasive devices. Can Vet J. (2020) 61:481-98.

74. Layland J, Solaro RJ, Shah AM. Regulation of cardiac contractile function by troponin I phosphorylation. Cardiovasc Res. (2005) 66:12-21. doi: $10.1016 /$ j.cardiores.2004.12.022

75. Campbell AP, Smrcka AV. Targeting G protein-coupled receptor signaling by blocking G proteins. Nat Rev Drug Discovery. (2018) 17:789-803. doi: $10.1038 / \mathrm{nrd} .2018 .135$

76. Holt NF, Haspel KL. Vasopressin: a review of therapeutic applications. J Cardiothoracic Vasc Anesth. (2010) 24:330-47. doi: 10.1053/j.jvca.2009.09.006

77. Leone M, Boyle WA. Decreased vasopressin responsiveness in vasodilatory septic shock-like conditions. Crit Care Med. (2006) 34:1126-30. doi: 10.1097/01.CCM.0000206466.56669.BE

78. Levy B, Bollaert PE, Charpentier C, Nace L, Audibert G, Bauer P, et al. Comparison of norepinephrine and dobutamine to epinephrine for hemodynamics, lactate metabolism, and gastric tonometric variables in septic shock: a prospective, randomized study. Intensive Care Med. (1997) 23:282-7. doi: 10.1007/s001340050329

79. Annane D, Vignon P, Renault A, Ballaert PE, Charpentier C, Martin C, et al. Norepinephrine plus dobutamine vs. epinephrine alone for management of septic shock: a randomised trial. Lancet. (2007) 370:676-84. doi: 10.1016/S0140-6736(07)61344-0

80. Dellinger RP, Levy MM, Rhodes A, Annane D, Gerlach H, Opal SM, et al. Surviving sepsis campaign guidelines committee including the pediatric subgroup. Surviving sepsis campaign: international guidelines for management of severe sepsis and septic shock: 2012. Crit Care Med. (2013) 41:580-637. doi: 10.1007/s00134-012-2769-8

81. Skelding A, Valverde A. Sympathomimetics in veterinary species under anesthesia. Vet J. (2020) 258:105455. doi: 10.1016/j.tvjl.2020.105455

82. Vail E, Gershengorn HB, Hua M, Walkey AJ, Rubenfeld G, Wunsch $\mathrm{H}$. Association between US norepinephrine shortage and mortality among patients with septic shock. JAMA. (2017) 317:1433-42. doi: 10.1001/jama.2017.2841

83. Finberg JP, Syrop HA, Better OS. Blunted pressor response to angiotensin and sympathomimetic amines in bile-duct ligated dogs. Clin Sci. (1981) 61:535-9. doi: 10.1042/cs0610535

84. Akinaga J, Lima V, Kiguti LR, Hebeler-Barbosa F, AlcántaraHernández J, García-Sáinz JA, et al. Differential phosphorylation, desensitization, and internalization of $\alpha 1 \mathrm{~A}$-adrenoceptors activated by norepinephrine and oxymetazoline. Mol Pharmacol. (2013) 83:870-81. doi: $10.1124 / \mathrm{mol} .112 .082313$

85. He X, Su F, Taccone FS, Laporte R, Kjolbye AL, Zhang J, et al. A selective $V_{1 A}$ receptor agonist, selepressin, is superior to arginine vasopressin and to norepinephrine in ovine septic shock. Crit Care Med. (2016) 44:23-31. doi: 10.1097/CCM.000000000000 1380

86. Jenkins CR, Gomersall CD, Leung P, Joynt GM. Outcome of patients receiving high dose vasopressor therapy: a retrospective cohort study. Anaesth Intensive Care. (2009) 37:286-9. doi: 10.1177/0310057X090370 0212

87. Saw MM, Chandler B, Ho KM. Benefits and risks of using gelatin solution as a plasma expander for perioperative and critically ill patients: a meta-analysis. Anaesth Intensive Care. (2012) 40:17-32. doi: 10.1177/0310057X1204000104

88. Lewis SR, Pritchard MW, Evans DJW, Butler AR, Alderson P, Smith AF, et al. Colloids vs. crystalloids for fluid resuscitation in critically ill people. Cochrane Database Syst Rev. (2018) 8:CD000567. doi: 10.1002/14651858.CD000567.pub7
89. Adams HA, Schmitz CS, Baltes-Gotz B. Endocrine stress reaction, hemodynamics and recovery in total intravenous and inhalation anesthesia: Propofol vs. isoflurane. Anaesthetist. (1994) 43:730-7.

90. Connolly CM, Kramer GC, Hahn RG, Chaisson NF, Svensén CH, Kirschner $\mathrm{RA}$, et al. Isoflurane but not mechanical ventilation promotes extravascular fluid accumulation during crystalloid volume loading. Anesthesiology. (2003) 98:670-81. doi: 10.1097/00000542-200303000-00015

91. van der Heijden M, Verheij J, van Nieuw Amerongen GP, Groeneveld AB. Crystalloid or colloid fluid loading and pulmonary permeability, edema, and injury in septic and nonseptic critically ill patients with hypovolemia. Crit Care Med. (2009) 37:1275-81. doi: 10.1097/CCM.0b013e31819cedfd

92. Sakaue M, Hoffman BB. Glucocorticoids induce transcription and expression of the alpha 1B adrenergic receptor gene in DTT1 MF-2 smooth muscle cells. J Clin Invest. (1991) 88:385-9. doi: 10.1172/JCI115315

93. Jeremy JY, Dandona P. Inhibition by hydrocortisone of prostacyclin synthesis by rat aorta and its reversal with RU486. Endocrinology. (1986) 119:661-5. doi: 10.1210/endo-119-2-661

94. Bailey JM, Makheja AN, Pash J, Verma M. Corticosteroids suppress cyclooxygenase messenger RNA levels and prostanoid synthesis in cultured vascular cells. Biochem Biophys Res Commun. (1988) 157:1159-63. doi: 10.1016/S0006-291X(88)80995-1

95. Liu T, Zhang L, Joo D, Sun SC. NF-אB signaling in inflammation. Sig Transduct Target Ther. (2017) 2:17023. doi: 10.1038/sigtrans.2017.23

96. Radomski MW, Palmer RM, Moncada S. Glucocorticoids inhibit the expression of an inducible, but not the constitutive, nitric oxide synthase in vascular endothelial cells. Proc Natl Acad Sci USA. (1990) 87:10043-7. doi: $10.1073 /$ pnas.87.24.10043

97. Prigent H, Maxime V, Annane D. Clinical review: corticotherapy in sepsis. Crit Care. (2004) 8:122-9. doi: 10.1186/cc2374

98. Khanna A, English SW, Wang XS, Ham K, Tumlin J, Szerlip H, et al. Angiotensin II for the treatment of vasodilatory shock. N Engl J Med. (2017) 377:419-30. doi: 10.1056/NEJMoa1704154

99. Faber P, Ronald A, Millar BW. Methylthioninium chloride: pharmacology and clinical applications with special emphasis on nitric oxide mediated vasodilatory shock during cardiopulmonary bypass. Anaesthesia. (2005) 60:575-87. doi: 10.1111/j.1365-2044.2005.04185.x

100. Okamura T, Yoshida K, Toda N. Suppression by methylene blue of prostaglandin I2 in isolated dog renal arteries. J Pharmacol Exp Therap. (1990) 254:198-203.

101. Gertler R, Brown HC, Mitchell DH, Silvius EN. Dexmedetomidine: a novel sedative-analgesic agent. Proc (Bayl Univ Med Cent). (2001) 14:13-21. doi: 10.1080/08998280.2001.11927725

102. Geloen A, Chapelier K, Cividjian A, Dantony E, Rabilloud M, May CN, et al. Clonidine and dexmedetomidine increase the pressor response to norepinephrine in experimental sepsis: a pilot study. Crit Care Med. (2013) 41:e431-8. doi: 10.1097/CCM.0b013e3182986248

103. Morelli A, Sanfilippo F, Arnemann P, Hessler M, Kampmeier T, D'Edigio A, et al. The effect of propofol and dexmedetomidine sedation on norepinephrine requirements in septic shock patients: a crossover trial. Crit Care Med. (2019) 47:e89-95. doi: 10.1097/CCM.0000000000003520

Conflict of Interest: The author declares that the research was conducted in the absence of any commercial or financial relationships that could be construed as a potential conflict of interest.

Copyright $(\odot 2021$ Valverde. This is an open-access article distributed under the terms of the Creative Commons Attribution License (CC BY). The use, distribution or reproduction in other forums is permitted, provided the original author $(s)$ and the copyright owner(s) are credited and that the original publication in this journal is cited, in accordance with accepted academic practice. No use, distribution or reproduction is permitted which does not comply with these terms. 